\title{
Metabolic Syndrome in Indigenous Minorities of the North of Yakutia
}

\author{
Sargylana I. Sofronova, $\mathrm{PhD}^{1}$; Anna N. Romanova, $\mathrm{MD}^{1}$; Vyacheslav M. Nikolaev, $\mathrm{PhD}^{1}$; \\ Lubov D. Olesova, $\mathrm{PhD}^{1}$; Nadezhda K. Chirikova, $\mathrm{PhD}^{2}$ \\ ${ }^{1}$ Yakut Science Center of Complex Medical Problems \\ ${ }^{2}$ M. K. Ammosov North-Eastern Federal University \\ Yakutsk, the Republic of Sakha (Yakutia), Russia
}

\begin{abstract}
The aim of our research was to study the prevalence of MetS in the North of Yakutia. The study was conducted under expeditionary conditions in the northern regions of Yakutia in the places where the indigenous peoples of the North live. . A total of 686 people aged between 20 and 70 were examined in 4 districts: Anabarsky (Anabar), Nizhnekolymsky (Lower Kolyma), Verkhnekolymsky (Upper Kolyma), and Tomponsky (Tompo). In all regions, there was a high prevalence of hypertension, with the highest frequency in the Anabarsky District. The greatest frequency of MetS was found in the Evenks (56.7\%) and the lowest in the Chukchi (20\%). Women had higher MetS frequency than men, and differences between men and women are statistically significant, with the highest frequency in Evenks women. (International Journal of Biomedicine. 2018;8(3):232-234.)
\end{abstract}

Key Words: indigenous minorities $\bullet$ abdominal obesity $\bullet$ arterial hypertension $\bullet$ metabolic syndrome

\section{Abbreviations}

AO, abdominal obesity; AH, arterial hypertension; BMI, body mass index; CVD, cardiovascular disease; FPG, fasting plasma glucose; HDL-C, high-density lipoprotein cholesterol; IGT, impaired glucose tolerance; LDL-C, low-density cholesterol; MetS, metabolic syndrome; OGTT, oral glucose tolerance test; TG, triglycerides; WC, waist circumference.

\section{Introduction}

Cardiovascular disease (CVD) is one of the leading causes of mortality in the Republic of Sakha (Yakutia) (RS(Y)), as it is across Russia. According to the Federal State Statistics Service, the CVD morbidity rate of the population remained on the same level from 2013 to 2015, and the mortality decreased slightly by $0.9 \%$, making the mortality rate $45.4 \%$. (1) Despite the tendency to a reduction in the CVD mortality rate ( 403.7 per 100,000 population in $2013,406.5$ per 100,000 population in 2014 , and 386.7 per 100,000 population in $2015)$, the ischemic heart disease mortality rate $(152.3$ per 100,000 population in $2013,162.7$ per 100,000 population in 2014 , and 167.5 per 100,000 population in 2015 ), including

*Corresponding author: Sargylana I. Sofronova, PhD. Yakut Science Center of Complex Medical Problems. Yakutsk, the Republic of Sakha (Yakutia),Russia.E-mail: sara2208@mail.ru the myocardial infarction mortality rate (23.6, 23.2, and 37.7 per 100,000 population, respectively), tends to rise, A certain role in this process belongs to MetS. This syndrome is one of the widely discussed problems in modern medicine. The International Diabetes Federation (IDF) estimates that about $25 \%$ of the world's population has $\operatorname{MetS}^{(2)}$ although this estimate varies widely depending on the age, ethnicity, and gender of the population studied..$^{(3-7)}$ MetS is associated with increased CVD and all-cause mortality. ${ }^{(8,9)}$ The prevalence of MetS increases with age, especially in an average age group $(30 \%-40 \%){ }^{(10-12)}$ According to studies conducted in the early 2000 s, a significant increase in the prevalence of AH (44.6\%) and overweight (42.4\% in men and $51.7 \%$ in women) was noted among the indigenous population of Evenkia. ${ }^{(13)}$ In Yakutia, besides Yakuts, the native inhabitants, there are several indigenous minorities. The prevalence of MetS among these ethnic groups has not previously been studied. However, carrying out such a study among indigenous minorities of the 
North is of great clinical importance, given the changes in the traditional way of life and nutritional habits, as well as the high prevalence of hypertension.

The aim of our research was to study the prevalence of MetS in the North of Yakutia.

\section{Materials and Methods}

The study was conducted under expeditionary conditions in the northern regions of Yakutia in the places where the indigenous peoples of the North live. A total of 686 people aged between 20 and 70 were examined in 4 districts: Anabarsky (Anabar), Nizhnekolymsky (Lower Kolyma), Verkhnekolymsky (Upper Kolyma), and Tomponsky (Tompo) (Table 1). In the compared groups, women prevailed. For the comparative analysis, we created five groups based on ethnic grounds living in the researched districts (Table 2).

Inclusion criteria: representatives of indigenous minorities of the North of Yakutia (the Dolgans, the Evens, the Evenks, the Chukchi, the Yukagir). Exclusion criteria: representatives of non-indigenous nationality and the Yakuts. The sample was formed according to the administrative lists of employees of the settlements. The response was $76 \%$.

\section{Table 1.}

Gender characteristics of indigenous minorities of the researched districts of Yakutia

\begin{tabular}{|l|c|c|c|c|}
\hline \multicolumn{1}{|c|}{ Variable } & Anabar & $\begin{array}{c}\text { Lower } \\
\text { Kolyma }\end{array}$ & $\begin{array}{c}\text { Upper } \\
\text { Kolyma }\end{array}$ & Tompo \\
\hline Total & 274 & 182 & 89 & 141 \\
\hline Men & $81(29.6 \%)$ & $66(36.3 \%)$ & $35(39.3 \%)$ & $51(36.2 \%)$ \\
\hline Women & $193(70.4 \%)$ & $116(63.7)$ & $54(60.7 \%)$ & $90(63.8 \%)$ \\
\hline Average age, yrs & $46.33 \pm 0.81$ & $47.04 \pm 0.87$ & $47.3 \pm 2.5$ & $43.02 \pm 0.98$ \\
\hline
\end{tabular}

\section{Table 2.}

Gender characteristics of indigenous minorities of Yakutia based on ethnic grounds

\begin{tabular}{|l|c|c|c|c|c|}
\hline Variable & Dolgans & Evens & Evenks & Chukchi & Yukaghirs \\
\hline Total, $\mathrm{n}$ & 85 & 141 & 67 & 40 & 77 \\
\hline $\begin{array}{l}\text { Men, } \\
\mathrm{n}(\%)\end{array}$ & $26(30.6 \%)$ & $51(36.2 \%)$ & $13(19.4 \%)$ & $20(50 \%)$ & $34(44.2 \%)$ \\
\hline $\begin{array}{l}\text { Women, } \\
\mathrm{n}(\%)\end{array}$ & $59(69.4 \%)$ & $90(63.8 \%)$ & $54(80.6 \%)$ & $20(50 \%)$ & $43(55.8 \%)$ \\
\hline $\begin{array}{l}\text { Average } \\
\text { age, yrs }\end{array}$ & $44.93 \pm 1.56$ & $43.02 \pm 0.98$ & $48.37 \pm 1.64$ & $39.73 \pm 1.93$ & $46.49 \pm 1.54$ \\
\hline
\end{tabular}

The study was approved by the Ethics Committee of the Yakut Science Center of Complex Medical Problems. Written informed consent was obtained from each patient.

A comprehensive clinical examination and laboratory tests included the following procedures:

- Anthopometrical reference data: BMI was calculated using Quetelet's formula (in $\mathrm{kg} / \mathrm{cm}^{2}$ ). Measurement of WC was made at the uppermost lateral border of the ilium using a tape measure (in $\mathrm{cm}$ )

- Assessment of blood pressure by Korotkov's method.

- Assessment of FPG, OGTT, and blood levels of TG, HDL-C, LDL-C.

MetS was diagnosed according to the Russian national recommendations (the All-Russian Scientific Society of Cardiologists [VNOK, 2009]) ${ }^{(14)}$ based on the IDF consensus criteria (2006). ${ }^{(15)}$ According to the that definition, the MetS is present when WC is increased $(\geq 94 \mathrm{~cm}$ in males and $\geq 80 \mathrm{~cm}$ in females (for Europids)) and at least two of the following factors are present: raised TG $(\geq 1.7 \mathrm{mmol} / \mathrm{l})$; reduced HDL-C $(<1.0 \mathrm{mmol} / 1$ in males and $<1.2 \mathrm{mmol} / 1$ in females $)$; increased LDL-C (>3.0 mmol/1); systolic blood pressure $\geq 130 \mathrm{mmHg}$ or diastolic blood pressure $\geq 85 \mathrm{mmHg}$; raised FPG $(>6.1$ $\mathrm{mmol} / \mathrm{l})$ and or IGT (OGTT $\geq 7.8 \mathrm{mmol} / \mathrm{l}$ and $\leq 11.1 \mathrm{mmol} / \mathrm{l}$ ). IGT $2 \mathrm{Hr} P G \geq 7.8 \mathrm{mmol} / 1$ and $\leq 11 \mathrm{mmol} / 1$.

Statistical analysis was performed using SPSS (version 17.0). Baseline characteristics were summarized as frequencies and percentages for categorical variables and as mean $\pm \mathrm{SEM}$ for continuous variables. The frequencies of categorical variables were compared using the Chi-square test. A probability value of $P<0.05$ was considered statistically significant.

\section{Results}

The research was conducted within two research projects: "The contribution of MetS to the development of coronary artery atherosclerosis in Yakutia residents" and "Development of new technologies for the treatment and prognosis of the risk of arterial hypertension and stroke in RS(Y) (State Contract No. 1133)."

In all regions, there was a high prevalence of hypertension, with the highest frequency in the Anabarsky District (Fig.1). In all groups, there was a high frequency of $\mathrm{AO}$ (from $47.5 \%$ in the Chukchi to $79.1 \%$ in the Evenks) (Fig.2). We found statistically significant differences in the frequency of $\mathrm{AO}$ in women compared with men. However, it is necessary to notice that there was equally high frequency of AO in Yukaghirs men and women in comparison with other ethnoses.

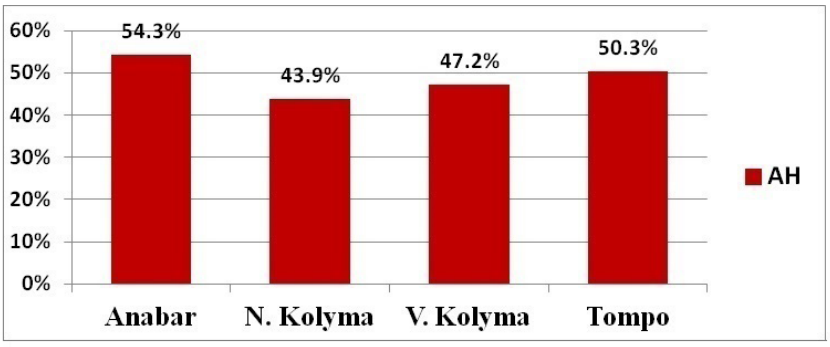

Fig. 1. Prevalence of AH in the researched districts of Yakutia.

We compared the frequency of MetS in the surveyed ethnic groups in accordance with the VNOK criteria (Fig.3). The greatest frequency of MetS was found in the Evenks (56.7\%) and the lowest in the Chukchi (20\%). Such a large difference in the MetS frequency was due to gender differences in these groups 


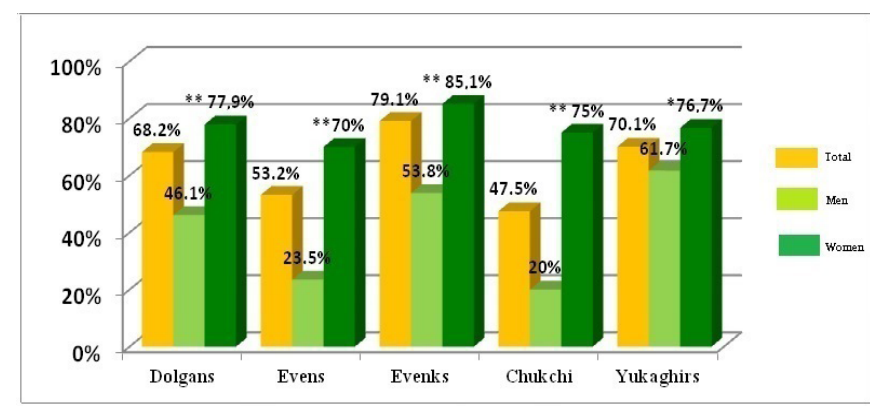

Fig. 2. Prevalence of $A O$ in indigenous minorities $\left(* *_{-} P<0.001\right.$ and $*_{-} P<0.05-$ between women and men).

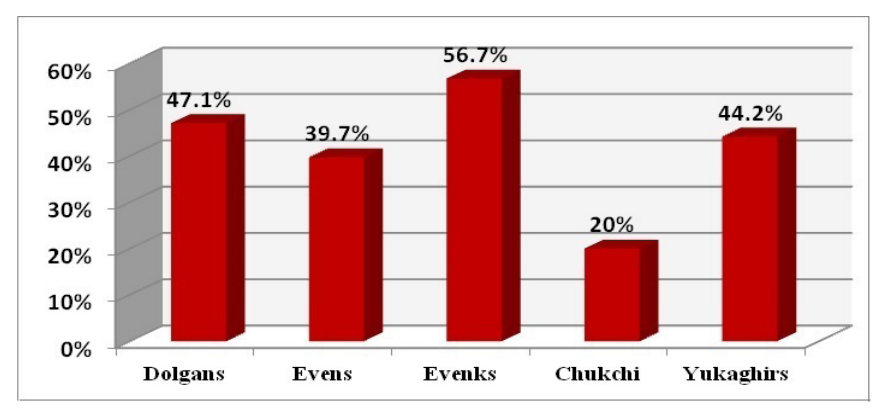

Fig. 3. MetS frequency in the surveyed ethnic groups.

Considering the traditional, historically developed, essential differences in the level of physical activity and other characteristics of lifestyle between men and women, the MetS frequency assessment in the compared groups was carried out separately for them (Fig.4). Women made a significant contribution to the frequency of MetS among the adult population. Women had higher MetS frequency than men, and differences between men and women are statistically significant, with the highest frequency in Evenks women (61.1\%).

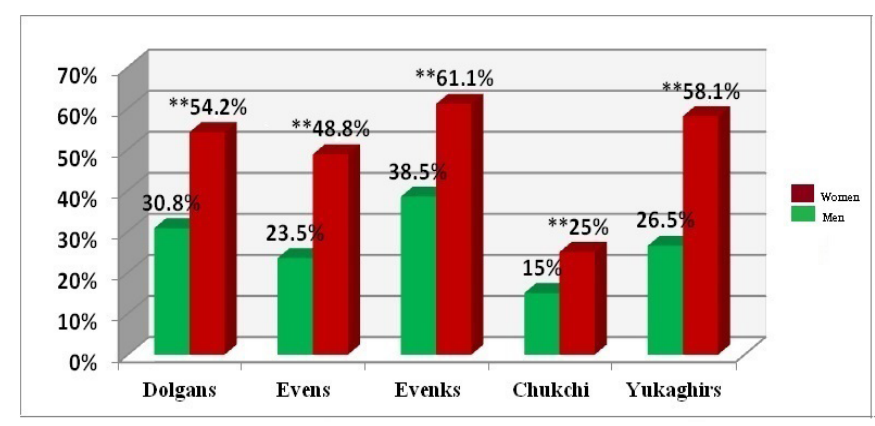

Fig. 4. MetS frequency in the surveyed ethnic groups depending on gender ( $* *_{-} P<0.001$ - between women and men).

In conclusion, we found a high prevalence of arterial hypertension in the remote northern regions of the RS(Y), where the representatives of indigenous minorities of the North live. The high risk of cardiovascular complications points out the necessity of further in-depth study of all factors affecting the health of the population in the areas of compact residence of indigenous minorities of Yakutia. Our study shows a high frequency of metabolic syndrome in the examined ethnic groups, which is caused by a change in the traditional lifestyle, the nature of nutrition, and low physical activity. The highest frequency of metabolic syndrome was observed in women. In the public health arena, the desirable way to reduce MetS is by lifestyle intervention, especially weight reduction, increased physical activity, and an anti-atherogenic diet.

\section{Competing interests}

The authors declare that they have no competing interests.

\section{References}

1. Health in the Republic Sakha (Yakutia): State Statistics of Sakha Republic (Yakutia).Yakutsk, 2016.

2. O'Neill S, O’Driscoll L. Metabolic syndrome: a closer look at the growing epidemic and its associated pathologies. Obes Rev. 2015;16(1):1-12. doi: 10.1111/obr.12229.

3. Kaur J. A comprehensive review on metabolic syndrome. Cardiol Res Pract. 2014;2014:943162. doi: 10.1155/2014/943162. 4. Beltran-Sanchez H, Harhay MO, Harhay MM, McElligott S. Prevalence and trends of metabolic syndrome in the adult U.S. population, 1999-2010. J Am Coll Cardiol. 2013;62(8):697-703. doi: 10.1016/j.jacc.2013.05.064.

5. DECODA Study Group. Prevalence of the metabolic syndrome in populations of Asian origin. Comparison of the IDF definition with the NCEP definition. Diabetes Res Clin Pract. 2007;76(1):57-67.

6. Assmann G, Guerra R, Fox G, Cullen P, Schulte H, Willett D, Grundy SM. Harmonizing the definition of the metabolic syndrome: comparison of the criteria of the Adult Treatment Panel III and the International Diabetes Federation in United States American and European populations. Am J Cardiol. 2007;99(4):541-8.

7. Ford ES. Prevalence of the metabolic syndrome in US populations. Endocrinol Metab Clin North Am. 2004;33(2):333-50.

8. Ford ES. Risks for all-cause mortality, cardiovascular disease, and diabetes associated with the metabolic syndrome: a summary of the evidence. Diabetes Care. 2005;28(7):1769-78. 9. Gami AS, Witt BJ, Howard DE, Erwin PJ, Gami LA, Somers VK, et al. Metabolic syndrome and risk of incident cardiovascular events and death: a systematic review and meta-analysis of longitudinal studies. J Am Coll Cardiol. 2007;49(4):403-14.

10. Ametov AS. [Obesity - epidemic XXI century]. Ter Arkh. 2002;74(10):5-7. [Article in Russian].

11. Grundy SM, Cleeman JI, Daniels SR, Donato KA, Eckel RH, Franklin BA, et al.; American Heart Association; National Heart, Lung, and Blood Institute. Diagnosis and management of the metabolic syndrome: an American Heart Association/ National Heart, Lung, and Blood Institute Scientific Statement. Circulation. 2005;112(17):2735-52.

12. Zimmet P, Shaw J, Alberti KG. Preventing Type 2 diabetes and the dysmetabolic syndrome in the real world: a realistic view. Diabet Med. 2003;20(9):693-702.

13. Khamnagadaev II. Prevalence of arterial hypertension, ischemic heart disease and their risk factors in the rural indigenous population of the North and Central Siberia. Abstract of ScD Thesis. Tomsk, 2008. [In Russian].

14. Metabolic syndrome diagnostics and treatment. Compilation of national recommendations. Moscow: SiliceaPoligraf Publishers; 2009:106-143. [In Russian].

15. IDF Consensus Worldwide Definition of the Metabolic Syndrome, 2006. Available from: https://www.idf.org/elibrary/consensus-statements/60-idfconsensus-worldwidedefinitionof-the-metabolic-syndrome 